\title{
ARTIGO
}

DOI: https://doi.org/10.22481/praxis.v14i29.4111

\section{NUEVOS SENTIDOS EN LA FORMACIÓN DOCENTE EN URUGUAY: EL INCIPIENTE DESARROLLO DE LO PRIVADO Y LAS ALTERACIONES DEL ETHOS MAGISTERIAL}

\author{
NEW MEANINGS IN TEACHER TRAINING IN URUGUAY: \\ THE EMERGING DEVELOPMENT OF THE PRIVATE AREA AND THE \\ ALTERATIONS OF THE TEACHING ETHOS
}

NOVOS SENTIDOS NA FORMAÇÃO DE PROFESSORES NO URUGUAI: O DESENVOLVIMENTO RECENTE DO PRIVADO E AS ALTERAÇÕES DO ETHOS DE MAGISTÉRIO

Eloísa Bordoli

Universidad de la República - Uruguay

Luis Domínguez

Universidad de la República - Uruguay

\begin{abstract}
Resumo: Permitir o desenvolvimento de universidades privadas no Uruguai - realizado no quadro dos decretos da última ditadura cívico-militar - permitiu a instalação da formação terciária privada. Neste contexto, o artigo pretende analisar o desenvolvimento da formação privada de professores nas últimas décadas. Em particular, busca identificar e analisar o surgimento dessas ofertas, bem como os processos de resignificação dos significados da formação de professores no zeitgeist neoliberal em que se baseia a Nova Gestão Pública. Na desvalorização do público, há uma alteração nos significados na formação de professores de ensino básico, bem como no ethos do magistério que foi criado no Uruguai moderno. $\mathrm{O}$ foco é estabelecido em dois momentos: inicialmente, identifica-se a matriz de significado e a produção do etos em magistério articulados em torno do modelo de significantes e do trabalho integracionista vinculado à homogeneização da igualdade. Num segundo momento, investigam-se em torno das alterações dos sentidos operados na formação de professores de ensino básico como consequência das oportunidades de formação privada. Neste contexto, identificam-se as divisões e disputas de significados que se estabelecem. O trabalho heurístico é desenvolvido a partir de uma perspectiva pedagógica crítica, se baseia em algumas noções da Análise do Discurso (LACLAU; MOUFFE, 1987). Metodologicamente, trabalhamos com documentos de naturezas varias para identificar os deslocamentos de significados na formação de professores.
\end{abstract}

Palavras-chave: Formação de professores. Privatização. Novos significados.

Abstract: Enabling the development of private universities in Uruguay - carried out in one of the last decrees of the last civic-military dictatorship - allowed the installation of private tertiary education. In this framework, this article aims to analyze the development of private teacher training in recent decades. In particular, it seeks to identify and analyze the emergence of these offers, as well as the processes of resignifying the meanings of teacher training in the neoliberal zeitgeist on which the New Public Management is based. The depreciation of the public sphere alters the meanings in teacher training, as well as in the teaching ethos that was developed in modern-day Uruguay. The focus is 
established in two moments: first, the matrix of meaning and the production of the teaching ethos articulated around the signifiers model and integrationist work, the latter tied to homogenizing equality, are identified. In a second moment, a research is carried out around the alterations of senses operated in teacher training as a consequence of the private option. Within this framework, cleavages and disputes of meanings that the emerging private option establishes are identified. The heuristic work is developed from a critical pedagogical approach, while it is based on some notions of the Political Analysis of Discourse (LACLAU; MOUFFE, 1987). Methodologically speaking, documents of various nature are used in this work in order to identify the displacement of meanings in teacher training.

Keywords: Teacher training. Privatization. New meanings

Resumen: La habilitación del desarrollo de universidades privadas en Uruguay - efectuado en uno de los últimos decretos de la dictadura cívico - militar - permitió la instalación de la formación terciara privada. En este marco, el artículo tiene por objetivo analizar el desarrollo de la formación docente privada en las últimas décadas. Particularmente, se busca identificar y analizar la emergencia de estas ofertas, así como los procesos de resignificación de los sentidos de la formación docente en el zeitgeist neoliberal sobre el que se asienta la Nueva Gestión Pública. Sobre el desvalor de lo público se opera una alteración de sentidos en la formación de docentes, así como en el ethos magisterial que se gestó en el Uruguay moderno. El foco se establece en dos momentos; inicialmente se identifica la matriz de sentido y la producción del ethos magisterial articulado en torno a los significantes modelo y labor integracionista amarrada a una igualdad homogeneizante. En un segundo momento, se indaga en torno a las alteraciones de sentidos operadas en la formación de docentes como consecuencia de la oferta privada. En este marco se identifican los clivajes y disputas de sentidos que la incipiente oferta privada instaura. El trabajo heurístico se desarrolla desde una perspectiva pedagógica crítica al tiempo que se apoya en algunas nociones del Análisis Político del Discurso (LACLAU; MOUFFE, 1987). Metodológicamente se trabaja con documentos de diversa naturaleza a los efectos de identificar los desplazamientos de sentidos en la formación docente.

Palabras clave: Formación docente. Privatización. Nuevos sentidos.

\section{Introducción}

En el Uruguay, al igual que en el conjunto de los países latinoamericanos, en el último tercio del siglo XIX se inicia la conformación de un nuevo orden económico, social, cultural y simbólico. En este particular período se operan nuevos anudamientos de sentido que legitimarán las bases del Uruguay moderno. A las transformaciones infraestructurales, sociales y políticas se añadirán tres movimientos: la unificación territorial, la monopolización estatal y la ciudanización de la autoridad. En este marco, la escuela pública uruguaya jugó un rol sustantivo, por medio de la unificación y centralización del sistema educativo, así como por la temprana formación de los sujetos especializados (los maestros) para impartir la "lengua nacional", los valores nacionales, los hábitos y conocimientos básicos que permitieran apartar los vicios y males provenientes de la ignorancia. En términos del 
historiador José Pedro Barrán el nuevo modelo de producción fue solidario e implicó cambios culturales y alteraciones en la sensibilidad de los sujetos; estas modificaciones en el sentir fueron necesarias para que se operaran modificaciones sustanciales en la conducta de aquellos tipificados como "bárbaros salvajes" (los gauchos) y "bárbaros etarios" (los niños) (BARRÁN, 1990, p. 21 y ss).

En este proceso la escuela pública y los maestros serán asociados con metáforas tales como: "luz", "alimento", "reforma salvadora", "camino", "remedio", "misión de paz", etc.. Como expresa el inspector de la Dirección General de Instrucción Pública de la época, Abel Pérez, la educación es “el factor irremplazable de nuestra transformación nacional” (PÉREZ, 1910, p. 6, en VARELA, 1910 a, p. 6).

Concomitantemente al proceso de creación del sistema educativo moderno, centralizado y estatal (PUIGGRÓS, 1990), se desarrolla un programa integral de formación de maestros a partir del Proyecto de Ley de Educación Común del 24 de agosto de 1877, impulsado por José Pedro Varela ${ }^{1}$.

Interesa recuperar esta matriz fundante de la escuela moderna así como configuradora del ethos del maestro y de su proceso de formación a los efectos de apreciar dos aspectos: a) el neto desarrollo público que la formación de docentes ha tenido en la historia del Uruguay moderno; b) las alteraciones de sentido y procesos de resemantización que en las últimas décadas se están operando en relación a la educación y, particularmente, a la formación docente.

Como desarrollaremos en los siguientes apartados, en uno de los últimos decretos de $1 e y^{2}$ de la dictadura cívico-militar, el Consejo de Estado habilita y reconoce los títulos universitarios que otorguen las universidades privadas. Este decreto, convalidado en 1985 por el primer parlamento en la recuperación democrática, posibilitó la creación y desarrollo de institutos y universidades privadas $\mathrm{y}$, de esta forma, el progresivo incremento de carreras universitarias y terciarias privadas. En este contexto, propicio para la generación de

\footnotetext{
${ }^{1}$ Si bien en el período pre-vareliano ya existían modalidades de formación de maestros no tenían un carácter integral. Como antecedentes se pueden citar: 1827 la creación de una escuela Normal en Guadalupe, Canelones; 1847 - 1849 al crearse el Instituto de Instrucción Pública se prevé la instalación de una Escuela Normal; los cursos normales para la formación de maestros desarrollados por la Sociedad de Amigos de la Educación Popular en 1868 y las lecciones de Berra hacia 1874, entre otros. Para un mayor desarrollo se puede consultar: DEMARCHI, 1996; DELIO; 2009; MENA SEGARRA, PALOMEQUE \& DELIO, 2011; BORDOLI, 2015, entre otros).

${ }^{2}$ El Consejo de Estado, integrado por los dictadores Gregorio Álvarez y Armando López Scavino, sanciona el Decreto-Ley 15.661 el 29 de octubre de 1984. Este establece en su artículo uno que: "Los títulos profesionales que otorguen las Universidades Privadas, cuyo funcionamiento haya sido aprobado por el Poder Ejecutivo, para su validez deberán ser registrados ante el Ministerio de Educación y Cultura, que organizará el Registro correspondiente".
} 
instituciones privadas, resalta el hecho de que la formación docente haya demorado dos décadas en iniciar su desarrollo ${ }^{3}$. Si bien a nivel de educación inicial y de postgrados el surgimiento de la oferta privada fue en la década de los noventa, las carreras de grado de profesores y maestros privados se iniciaron entrado el nuevo milenio.

Excede el alcance de este artículo ubicar las claves explicativas de este "retraso" en la oferta de formación docente privada si se compara al Uruguay con el conjunto de los países latinoamericanos así como a nivel internacional. No obstante, y a modo de hipótesis de futuras investigaciones, es posible señalar que, al menos, tres factores han podido incidir. En este sentido el carácter heterodoxo o amortiguado de la reforma de corte neoliberal de los $90^{\circ}$ así como la peculiar forma, moderada y gradualista, de procesar los cambios que la cultura política uruguaya ${ }^{4}$ posee configuran dos elementos que podrían dar cuenta del tardío e incipiente desarrollo de la oferta de formación docente privada. Un tercer elemento podría relacionarse con la matriz pública de la educación y la formación docente así como la valoración positiva en torno a estos dos aspectos (lo público-estatal y la educación). Esta matriz se asienta en la articulación de sentidos en torno al valor integracionista e igualitarista que la educación y la acción pedagógica de los maestros tuvo en el seno de la sociedad. Sobre este tercer elemento, la utopía decimonónica desarrollada en torno a la educación, volveremos en el apartado siguiente con el objetivo de precisar cómo la educación y quienes se forman para ejercerla en las escuelas públicas portan un poder civilizatorio cardinal al tiempo que coadyuvan en el entramado de lo social.

En el marco de estas constelaciones de sentido de lo educativo, configuradas históricamente, el objetivo de este artículo es identificar las asociaciones semánticas, así como las oposiciones de sentidos que dan cuenta de estas alteraciones significantes ${ }^{5}$. Particularmente, el foco analítico se establecerá en la génesis altamente estatista de la formación docente y en la producción de un ethos magisterial articulado con la función integracionista e integral de la educación y del desarrollo del valor de lo universal y de la

\footnotetext{
3 Como profundizaremos, hasta el año 2004 la formación docente era predominantemente pública. La única excepción lo constituyó el Magisterio María Auxiliadora, perteneciente a los Salesianos de la ciudad de Las Piedras, que en 1977 fue habilitado para preparar a los estudiantes de magisterio. Hasta esa fecha y desde 1905 año en que abre sus puertas- estos debían rendir un examen convalidatorio en el Instituto Normal para poder ejercer la docencia.

${ }^{4}$ Sobre estos aspectos se puede consultar: MOREIRA, C. (2001); LANZARO, J. (2004), BENTANCUR, N. (2008); entre otros.

5 En el marco del Análisis Político del Discurso (APD) la “(...) articulación consiste en la construcción de puntos nodales que fijan parcialmente el sentido (LACLAU; MOUFFE, 1987, p. 154). En otros términos, las operaciones de articulación de equivalencias y de diferenciación, al tiempo que instituyen a los sentidos excluyen otras posibles formulaciones. Es por ello que la práctica de articulación hegemónica se torna un espacio de disputa política. En términos de Laclau, son "los significantes vacíos [los] que unifican una cadena equivalencial" (LACLAU, 1996, p. 69).
} 
comprensión de la igualdad en clave de homogeneización. Asimismo, interesa apreciar cómo en las últimas décadas - sobre el desvalor de lo público que el zeitgeist neoliberal promulga y sobre el cual se asienta la Nueva Gestión Pública - se opera una alteración de sentidos en la formación de docentes, así como en el ethos magisterial. Sobre estas superficies discursivas, el incipiente desarrollo de carreras de maestros y profesores en instituciones universitarias privadas pone en evidencia y materializan la disputa que se opera en torno a lo público y al papel del Estado como garante del derecho a la educación así como al sentido de la formación de los docentes.

Desde una preocupación pedagógica y desde una perspectiva crítica, el trabajo de investigación se apoyó en algunas nociones del Análisis Político del Discurso (LACLAU \& MOUFFE, 1987). Metodológicamente se trabajó con documentos de diversa naturaleza; a partir de los cuales se identificaron recurrencias significantes a los efectos de apreciar las asociaciones o cadenas de equivalencias, así como las ausencias y antagonismos.

El artículo expone las primeras aproximaciones del trabajo heurístico realizado. Este se articula en tres apartados centrales. En el primero, se presenta la matriz de sentidos que se articuló en el Uruguay moderno en torno al papel de la educación en la sociedad y, específicamente, a los elementos que significaron el ethos magisterial. En el siguiente apartado se desarrollan, inicialmente, algunos de los debates que se suscitan en torno a las instituciones educativas terciarias y universitarias (como formación docente) y al clivaje operado entre los significantes pertinencia social y calidad, así como los diferentes modelos universitarios, funcionalista y democrático, que se hallan en disputa. A punto de partida de estos significantes en oposición se presentan algunos datos que dan cuenta de la incipiente pero progresiva concreción de la oferta de formación docente privada, así como las operaciones significantes que disputan lo público. Finalmente, en el último apartado se avanza en algunas conclusiones preliminares del trabajo de investigación.

\section{Tradiciones y sentidos de la Formación Docente}

\subsection{La matriz estatal garante de la igualdad homogeneizante}

(El único medio de solución de la crisis es) aumentar la capacidad productora del pueblo, y especialmente del paisano, y esto se conseguirá creándole hábitos de trabajo; no rodeándolo con una civilización que no comprende, sino civilizándolo. (VARELA, 1990 a, p. 57)

A los efectos de este trabajo, interesa subrayar que para el reformador uruguayo, José Pedro Varela, la formación de maestros se debe procesar en el ámbito público en tanto el 
Uruguay moderno se configura a partir de una utopía educacionista que se sustenta en el principio de igualdad y en el valor de lo universal. En estas construcciones de sentidos, José Pedro Varela en La educación del pueblo sostiene:

El principio dominante en la sociedad moderna es ese sentimiento de igualdad, que tiende, cada día más, a no establecer diferencia alguna entre las clases sociales, sobre todo respecto a la educación general. Un sistema de enseñanza pública que abra las puertas a unos y las cierre a otros, es, y debe ser, enérgicamente rechazado por ese sentimiento. (VARELA, 1910b, p. 89).

Más adelante agrega:

La igualdad no puede admitir un sistema de enseñanza secundaria que organice dos órdenes de establecimientos, de los que, unos solo formarían obreros o industriales, mientras que los otros prepararían y producirían los magistrados, los altos funcionarios, las personalidades prominentes del Estado. (VARELA, 1910b, p. 89).

Asimismo, en La legislación escolar Varela insiste con estas articulaciones de sentido. En ese texto plantea: "Los progresos de la ciencia y de la educación difundida a todos, destruirán el baluarte donde las castas privilegiadas se amurallaban” (VARELA, 1910 a, p. 126).

Como se desprende de los enunciados precedentes, la educación se delinea como un factor clave en el proceso de gestación del Uruguay moderno en tanto habilitador de nuevas formas de integración de la fragmentada sociedad. En este marco, la igualdad se erige en uno de los principios cardinales para el desarrollo de la educación pública. Como señalan diversas investigaciones, la igualdad fue construida en clave de homogeneidad en tanto no contempló la diversidad social y cultural al tiempo que apuntó a imponer un modelo "civilizatorio" particular. No obstante, también articuló un sentido de integración social en el marco del cual la enseñanza pública debía combatir los antagonismos sociales. De forma imaginaria o como horizonte utópico educación e igualdad se enlazaron al tiempo que interpelaron al Estado como agente garante del proceso de desarrollo de este binomio.

La conformación de un sistema de escuelas públicas en todo el territorio nacional exigió la formación de un cuerpo especializado: los maestros.

\subsection{El ethos magisterial: modela, iguala e integra (ejército de túnicas blancas)}

A partir de los sentidos forjados en el naciente Estado y con la notoria influencia vareliana es interesante recordar que en 1892 y en 1891 comenzaron a funcionar en 
Montevideo el Internado Normal de Señoritas y el de Varones respectivamente, que dejan de recibir estudiantes internos a partir de 1900, iniciando un proceso de transformación de internatos a institutos normales. En los albores del siglo XX, la titulación de maestro de primer grado podía obtenerse de tres maneras: el título habilitado por los internatos, el otorgado por los institutos normales en proceso de creación y el obtenido por exámenes libres de suficiencia (DELIO, 2009). Esta situación era definida como de crisis por las propias autoridades de la época, que instalaron la formación docente como problema del Estado.

En este marco, el ejército de túnicas blancas se asienta en la tradición normalizadora disciplinadora (DICKER \& TERIGI, 2008) propia de los sistemas educativos públicos modernos. El caso del Uruguay no es una excepción: la reforma educativa vareliana, de fuerte impronta positivista, es el punto donde se sientan las bases de esta tradición. La premisa de que la educación, como la luz del sol, puede y debe llegar a todos, traduce la intención del estado de homogeneización de la población heterogénea y diversa. Esta función normalizadora de la novel escuela pública se tradujo en una alfabetización básica y una fuerte búsqueda de integración moral que hicieran posible la cohesión social. En esta línea es posible señalar que la sociedad es hija de la escuela pública, encargada desde sus orígenes de impartir conocimientos básicos y, sobre todo, valores comunes necesarios para la constitución de una identidad colectiva. Precisamente, esta es la misión de la escuela y el marco sobre el cual los maestros se constituirán en misioneros laicos del Estado educador. Alliaud (1993) los llamará la legión de maestros patrioteros. En la búsqueda de la referida integración moral, el papel disciplinador fue notorio: la lógica de premios y castigos no se aplicó solamente a los alumnos, sino también a los docentes. Éstos debían ser modelos, referentes de una cultura y un saber (básico, restringido a lo escolar y desconocedor de otras culturas y saberes) y, por otro lado, poseedores de una moral intachable.

La formación normal del maestro se ubicó en un nivel medio (sería referente de un saber disciplinar básico, no de elevado nivel científico técnico). A su vez, la docencia se volvió una ocupación fundamentalmente femenina lo que coadyuvó a la imagen de la maestra como "segunda madre". Esto dotó a la misión del ejército blanco de una fuerte carga afectiva, acrecentada por el cumplimiento de labores comunitarias (por ejemplo, la promoción de la salud y la higiene) que iban mucho más allá de la trasmisión de saberes.

En virtud de estos elementos, la imagen del buen maestro construida desde fines del siglo XIX está caracterizada por tres rasgos básicos:

1) La posesión de saberes disciplinares básicos, los necesarios para alfabetizar y homogeneizar a un conjunto de niños de diversa procedencia social y cultural. El maestro está 
encargado de difundir un sistema de valores único y legítimo. No concibe la imprevisibilidad e indeterminación en la enseñanza.

2) Una moral intachable, caracterizada por la austeridad y la disciplina que constituían al docente en un modelo, un deber ser.

3) Una entrega afectiva a su ocupación con una clara conciencia de su función de guía y apoyo a las familias y comunidad a las que ilumina y salva de la barbarie.

Así definido, el maestro era más rico en recompensas simbólicas que en recompensas materiales. Las ideas de entrega y sacrificio, propias del apóstol, implicaron la construcción de un modelo, un ethos magisterial que al tiempo que se erigía como figura ejemplarizante tenía el deber de moldear a los bárbaros etarios y a los bárbaros salvajes.

Como se adelantó en la sección anterior y en forma paralela a los elementos modélicos y normalizadores descritos el ethos magisterial también se configuró en torno a la figura que representaría al Estado en la misión de formar a las nuevas generaciones e integrar la fragmentada y desigual sociedad. En este sentido, afirma el Dr. Abel Pérez, Inspector Nacional de Instrucción Primaria:

[...] es indiscutible que una carrera que tiene tantas proyecciones sociales, que tan profundamente interesa al porvenir de nuestras nacionalidades y que tan eficazmente reclama la acción directa e indirecta del Estado, no puede ni debe ser algo que esté entregado a la voluntad de cada uno (...) el Estado [debe] crear no una, sino varias escuelas o Institutos Normales, que aseguren para un plazo lo más cercano posible, un número suficiente de maestros formados bajo su vigilancia consciente e ilustrada, para colocar al frente de cada escuela pública, de manera que cada uno de esos representantes de la institución pública en el país, ofrezca en su actuación normal la garantía más indiscutible de su actuación pública, es decir, de su papel más importante al coadyuvar eficazmente a la formación de las generaciones de ciudadanos a quienes la patria va a confiar su porvenir. (PÉREZ, 1904, pp. 83-84 en DELIO, 2009, pp. 161-162)

Para el desarrollo argumentativo de este trabajo, interesa particularmente reparar en las asociaciones de sentidos que se establecen. En esta línea, la carrera de los maestros se articula con las demandas de integración social y de búsqueda de mayores niveles de igualdad. Esto implica que la misión del maestro se gesta conjuntamente con la responsabilidad del Estado y, más aún, se configura con esta.

En el análisis de los documentos del período, especialmente en los escritos de Varela y en los Anales de Instrucción Primaria es posible identificar el papel de integración y sutura social que la escuela pública y la función del maestro, al amparo del Estado, desempeñarían. Enunciados tales como: "las escuelas públicas (...) abren sus puertas a todos los alumnos, sin 
distinción de clases" (Dirección General de Instrucción Primaria, DGIP, 1903, p.3) o "ninguna misión es más grande que la del maestro de escuela (...) que deja huellas imperecederas en la sociedad" (VARELA, 1910 b, p. 324) reflejan con meridiana claridad la responsabilidad del Estado y el valor de lo público no solo en la educación general sino en la formación de los maestros. Estos elementos configurarán un ethos asentado en la función modélica y normalizadora así como en el imaginario igualitarista e integrador que la escuela y la labor del maestro desarrollarán.

\section{Alteraciones en la matriz estatal de la formación docente y procesos de resignificación del ethos magisterial}

En este apartado se trabaja en torno a las disputas de sentido acaecidas a nivel de la educación terciaria y universitaria. Inicialmente, se enfatizan las construcciones de sentido y los antagonismos que se generan en torno a los significantes calidad y pertinencia social así como a las tensiones operadas entre los modelos universitarios articulados en torno a una lógica funcionalista y los articulados desde una perspectiva democrática. En un segundo momento, se trabaja sobre la incipiente oferta de formación docente privada en el Uruguay. En este punto se describen las propuestas y se analizan las tensiones que esta nueva oferta genera en la trama de sentidos educativos históricamente sedimentados. Finalmente, se presta atención a los procesos de resignificación del ethos magisterial que se opera a partir de la alteración de la matriz estatal en la formación docente.

\subsection{Disputas en torno a las instituciones educativas terciarias y universitarias: pertinencia / calidad y funcionalismo / autonomía}

En la superficie simbólica, pertinencia social y calidad, se configuran en significantes vacíos $^{6}$ (LACLAU; MOUFFE, 1987) sobre los cuales se disputa la inscripción de sentidos posibles en función de lógicas y modelos de universidad y enseñanza terciaria.

Desde este ángulo de mira, resulta de interés recuperar algunos de los debates en torno a estos significantes (pertinencia social y calidad) que se han operado en el marco de las

\footnotetext{
6 "Un significante vacío es, en el sentido estricto del término, un significante sin significado [... y este] solo puede surgir si la significación en cuanto tal está habitada por un imposible estructural, y si esta imposibilidad solo puede significarse a sí misma como interrupción [...] de la estructura del signo" (LACLAU, 1996, p. 6970). Además, "el significante vacío es un nombre y no un concepto y, por tanto, constituye el movimiento político como singularidad" (LACLAU; MOUFFE, 1987, p. 119).
} 
instituciones terciarias y universitarias. En esta línea, valoramos que no es posible plantear la tensión entre lo público y lo privado en la formación de docentes sin referir al para qué de la educación superior en las sociedades actuales, así como los diferentes modelos universitarios y de educación terciaria que se ponen en juego.

En términos generales, la universidad y la formación docente ${ }^{7}$ públicas en Uruguay se han caracterizado por ser abiertas a todos. Asimismo se han configurado en un bien público en tanto ligan a través del conocimiento el presente con el mediano y largo plazo y habilitan, de manera diferencial, el debate crítico y abierto (SOUSA SANTOS, citado en GENTILI, 2005).

No obstante, en las últimas décadas la omnipresencia de la lógica del mercado, el progresivo ataque a lo público y la emergencia de la denominada Nueva Gestión Pública han interpelado y permeado las diferentes esferas de la sociedad, así como a las universidades y la formación terciaria. A punto de partida de estas transformaciones Tünnermann y de Souza Chaui (2003, p.9) establecen una tipología de universidades entre las que se encuentran la operacional o funcional que, particularmente, prepara sujetos para el juego del mercado laboral y la democrática y autónoma que asume la educación como derecho y los valores democráticos como imperativos de lo universitario. Para el caso de Uruguay, y en relación a la pertinencia social de la universidad, Brovetto (1994) señala el riesgo de que esta responda exclusivamente a algún sector o demanda coyuntural específica en tanto se podría desvanecer el papel crítico del modelo universitario democrático y autónomo.

En términos de Vessuri (2008) la pertinencia social de lo educativo podría representarse como el reflejo de una utopía progresista solidaria que, en los hechos, ya estaba vulnerada a fines de los '90 por el fuerte empuje de la perspectiva neoliberal. Merced a esta, la discusión se desplaza desde la pertinencia a la calidad, reduciendo la primera a las demandas del mercado y transformándola en una dimensión medible de la segunda. En la perspectiva neoliberal es posible identificar una tríada educación superior-mercado-gobierno en la que este último regula y organiza sistemas de contralor de la calidad como derecho del consumidor. La formación es mercancía y las universidades son asimilables a empresas que compiten en el mercado educacional. Un exponente claro de esta concepción es el Banco Mundial, que en su publicación La enseñanza superior. Las lecciones derivadas de la experiencia propone (entre otras varias cosas) que "la duración de los programas

\footnotetext{
${ }^{7}$ En Uruguay la formación docente se inscribe en la enseñanza terciaria no universitaria. Desde hace más de una década se debate la inscripción universitaria de esta. En los últimos años se han presentado cuatro proyectos de creación de universidades de la Educación que puedan albergar a toda la formación docente inicial y continua. Estos proyectos no han contado con los apoyos parlamentarios necesarios para ser aprobados.
} 
profesionales debe estar determinada por los requisitos del lugar de trabajo más bien que por criterios académicos" (BANCO MUNDIAL, 1995, p. 84).

Frente al extremo neoliberal, Muñoz (2008) contrapone el triángulo educación superior-sociedad-Estado, denunciando al mercado como uno de los poderes que actualmente pretende dominar y poner a su servicio a las universidades e instituciones de educación superior, en un claro ataque a su autonomía y a la creatividad, espíritu crítico y rebeldía que hacen a la identidad de la educación superior. En esta concepción, el Estado reconoce la autonomía universitaria y le garantiza a la sociedad las condiciones de ejercer su derecho a una educación superior, brindada en instituciones que desarrollan en los individuos capacidades colectivas para la transformación social y no de mera adaptación individual a un mercado económico competitivo y alienante. En este mismo sentido, Tünnermann y de Souza Chaui (2003) van contra la aceptación del determinismo económico estableciendo que "la autonomía de la universidad pública (...), ha de ser definida ahora como rechazo de la tutela empresarial y financiera" (TÜNNERMANN; SOUZA CHAUI, 2003, p.10).

Sobre estas superficies discursivas en las que se ponen en juego las finalidades de la educación superior y el lugar del Estado así como los sentidos otorgados a los significantes pertinencia social y calidad se inscriben las nuevas instituciones terciarias y universitarias que ofrecen carreras de formación docente.

\subsection{La incipiente formación docente privada en Uruguay}

\subsubsection{Lo público y lo privado en la educación superior}

En términos generales, la educación privada se inscribe en la lógica del mercado, en la medida en que el usuario-cliente genera con la institución un vínculo comercial en virtud del cual está comprando un servicio ${ }^{8}$. En términos de Bourdieu (2000), estaría intercambiando, por un cierto capital económico, un servicio que asegura la provisión de un cierto capital cultural (y hasta social) que luego entrará en el juego de las reconversiones para el mantenimiento (y eventual mejora) de la situación de clase. En la sociedad actual, según Gentili, "existe un mercado educativo, donde se realizan los intercambios de bienes y servicios educacionales orientados a la satisfacción de las aspiraciones culturales y a la

\footnotetext{
${ }^{8}$ Cabe consignar que en Uruguay las instituciones educativas privadas se benefician con amplias exoneraciones impositivas así como por donaciones realizadas por empresas. A su vez, estas últimas al efectuar donaciones especiales a las instituciones educativas privadas logran importantes exoneraciones fiscales. Un desarrollo de estos aspectos se pueden consultar en: Bordoli, et. al, 2017.
} 
adquisición de títulos y certificados para el intercambio en otros mercados"9 (GENTILI, 2011, p.51). La posición de las universidades privadas en este mercado difiere sustancialmente de la que pueden sostener la mayoría de las universidades públicas, en virtud de sus fuentes de financiamiento (los aranceles cobrados a los estudiantes en las primeras, la asignación de recursos por parte del Estado en las segundas).

A nivel internacional, de Sousa Santos (2009) señala que la universidad pública, merced a la globalización neoliberal que se va imponiendo a partir de los '80, pierde lugares en la escala de prioridades de los Estados, que retroceden en tanto que Estados benefactores. En este contexto, la educación superior se diversifica y se da una notoria expansión de las universidades privadas, lo que supuso "la transformación de la universidad en un servicio al que se tiene acceso no por vía de la ciudadanía sino por vía del consumo, y, por lo tanto, mediante el pago, el derecho a la educación sufrió una erosión radical." (SOUSA SANTOS, 2009, p. 44). No deja de resultar paradójico, como señala Gajardo (2005), que las universidades privadas que no practican la democratización en su funcionamiento interno, se habiliten, precisamente, en el marco de las libertades que la democracia garantiza.

Las alianzas propuestas por el Banco Mundial entre las universidades y las empresas tienden a aumentar la injerencia de esta últimas "no sólo en la producción del discurso educativo hegemónico sino también en la gestión de los establecimientos escolares (...). Los procesos de privatización son siempre procesos de transferencia del poder de la esfera pública al mercado." (GENTILI, 2007, p. 30).

Si bien Uruguay dista de ser un caso emblemático de procesos de privatización de la educación, es necesario señalar que la habilitación de carreras de grado de maestros y profesores en la universidades privadas marca un quiebre con respecto al lugar que la escuela pública y la figura del maestro ha tenido en el proceso histórico.

Como se indicó precedentemente, el desarrollo de las instituciones terciarias y universitarias privadas en Uruguay ha sido tardío y moderado con respecto a los parámetros regionales e internacionales. Hasta $1985^{10}$, la Universidad de la República (UdelaR) era la única universidad reconocida como tal. En ese año, se legitima la Universidad Católica,

\footnotetext{
${ }^{9}$ El autor va aún más allá en su análisis del neoliberalismo en educación al afirmar: "En una coyuntura en la que el neoliberalismo político ha marcado el rumbo de nuestras sociedades cada vez más excluyentes y desiguales, el neoliberalismo académico ha ganado buena parte de las batallas libradas. "(GENTILI, 2011:63)

${ }^{10}$ El primer Parlamento luego de la dictadura cívico-militar convalidó el Decreto-Ley 15.661, de fines de 1984 posibilitando la creación de universidades privadas y confiando al MEC el control de procedimientos y registro de titulaciones.
} 


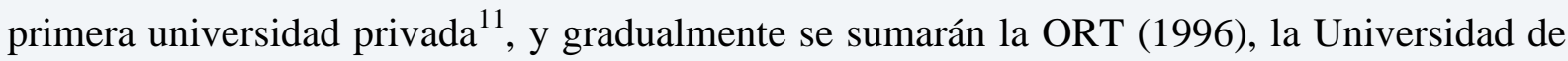
Montevideo (1997), la Universidad de la Empresa (1998) y dos institutos universitarios ${ }^{12}$. Entre los primeros cinco años del nuevo milenio se habilitaron nueve instituciones terciarias privadas más. En el año 2006 se autorizó un nuevo instituto universitario y entre 2011 y 2016 se habilitaron cuatro instituciones más. Como se deduce de las referencias efectuadas, el flujo de habilitación de las universidades privadas ha sido irregular. Prima face el enlentecimiento producido a partir de 2005 podría asociarse con la asunción del Frente Amplio al gobierno nacional. Esta coalición y movimiento de centro - izquierda ganó el gobierno en base a un discurso crítico al modelo neoliberal de los años precedentes y promovió la revalorización del rol del Estado. No obstante, el análisis particular de la evolución de la oferta educativa privada a nivel superior y sus interrelaciones con las orientaciones de los gobiernos excede el objetivo de este trabajo.

\subsubsection{La formación docente privada en el Uruguay}

En el marco de lo establecido hacia el final del apartado anterior, es particularmente interesante apreciar que se habilitan las primeras carreras de grado de profesores y maestros en el año 2009 y en el año 2010 respectivamente en una universidad privada, la Universidad de Montevideo $(\mathrm{UM})^{13}$. Con anterioridad a ello y como también adelantamos, la única institución privada que ofrecía una carrera docente habilitada por el Estado era el Instituto Magisterial María Auxiliadora, perteneciente a la congragación de los Salesianos. Actualmente, esta institución forma a Maestros de Educación Primaria y Maestros de Primera Infancia, siguiendo los planes de estudio oficiales, lo que habilita a sus egresados a ejercer en el ámbito público con las mismas prerrogativas que los docentes formados en el sistema estatal. Claro está, este centro agrega la formación cristiana, dado su carácter confesional.

\footnotetext{
${ }^{11}$ Ley General de Educación $N^{\circ} 18.437$ de 2008 establece en su artículo 82: "La educación terciaria privada se regirá por lo establecido en la Decreto-Ley N ${ }^{\circ} 15.661$, de 29 de octubre de 1984, y sus decretos reglamentarios.”

12 También entre 1996 y 1998 se habilitaron el Instituto Universitario Autónomo del Sur y el Instituto Universitario CLAEH, que es universidad a partir de 2017. El primero de ellos ya no funciona.

${ }^{13}$ Es necesario indicar que la formación de docentes, a nivel público, se desarrolla en un ente autónomo, la Administración Nacional de Educación Pública (ANEP) independiente de la Universidad de la ${ }^{\text {República }}$ así como del Ministerio de Educación y Cultura. Excede los límites de este trabajo historiar la formación docente pública: simplemente consignaremos que desde 2010 depende del Consejo de Formación en Educación (CFE), desconcentrado que responde al Consejo Directivo Central (CODICEN) de la ANEP. Por tanto, es a este organismo al que le corresponde la habilitación de las carreras docentes -de grado- en el sector privado, en el marco normativo de la Ordenanza $\mathrm{N}^{\circ} 14$ de 1994.
} 
Como establecimos, la Universidad de Montevideo (UM) fue la segunda institución habilitada oficialmente para expedir títulos de profesores y maestros. Para el caso del profesorado, la habilitación se dio luego de un complejo proceso -iniciado en 2004- en el que la habilitación llegó a ser revocada por el CODICEN de la ANEP ${ }^{14}$. Actualmente, la UM ofrece la carrera de profesorado en Filosofía, Historia, Literatura, Inglés y Matemática. Para los dos últimos, ofrece el plan Plus+ y el plan Suma respectivamente; estas propuestas apuntan a docentes ya en ejercicio, con titulación pendiente. En cuanto a la formación de maestros, ofrece el título de Maestro (título oficial) al que agrega el de Maestro bilingüe (título propio). Cabe consignar que estas carreras, si bien se ajustan a los currículos propuestos por el Estado, estos se hallan creditizados y, también, se han semestralizado algunas asignaturas, conservando los programas y cargas horarias. Además, la oferta incluye agregados con foco, fundamentalmente, en el bilingüismo y en el uso de las tecnologías de la información. Por lo demás, la UM no es de origen confesional, pero la prelatura del Opus Dei brinda asistencia espiritual a quienes libremente lo deseen, dando orientación cristiana a la propuesta educativa.

En el año 2013 obtuvo la habilitación el Instituto de Formación Docente Elbio Fernández (IFDEF), luego de haber sido creado en 2010 por la Sociedad de Amigos de la Educación Popular (SAEP). Forma maestros de educación primaria y actualmente se encuentra en trámite de reconocimiento ante el MEC la carrera de Licenciado en Educación Escolar, que se ofrece en el marco no del IFDEF, sino del IUEF (Instituto Universitario Elbio Fernández), aún en ciernes. Para el caso de magisterio, cumple con el Plan de estudios oficial, al que agrega la posibilidad de certificarse como maestro para la enseñanza del inglés en escuelas o como maestro bilingüe.

Hasta aquí hemos presentado a grandes rasgos las tres instituciones que brindan a sus egresados títulos docentes de grado equivalentes a los oficiales y que por tanto los habilitan para ejercer en los mismos contextos que los maestros y profesores egresados de los institutos dependientes del CFE de la ANEP. Existen otras dos instituciones privadas de educación superior que ofrecen carreras de grado de carácter docente, aunque éstas no se encuentran

14 Esta habilitación significó el fin del monopolio del Estado para la formación de profesores de Enseñanza Media. Inicialmente, la UM había solicitado la habilitación de la carrera en 2004. En diciembre de 2007 se otorgó la habilitación, que se suspendió en febrero de 2008, revocándose definitivamente dos meses después por errores jurídicos. La UM inició nuevamente los trámites de habilitación en mayo de ese año, obteniéndola en agosto de 2009. Esta habilitación fue fuertemente resistida por el gremio de profesores de Secundaria y por el de los estudiantes del Instituto de Profesores Artigas (principal instituto público de formación de profesores en Uruguay). 
habilitadas por ANEP (sí están reconocidas por el MEC). Estas son la Universidad Católica del Uruguay (UCU) y el Instituto Universitario Asociación Cristiana de Jóvenes (IUACJ).

La UCU ofrece, desde el año 1999, la Licenciatura en Educación Inicial, como carrera de 4 años con un perfil orientado a la atención de niños de 0 a 5 años y también a la gestión de proyectos e instituciones para la educación de la primera infancia. Sus egresados, según nos informó la institución, no pueden ejercer como docentes de educación inicial en instituciones públicas de la ANEP ni privadas habilitadas con niños mayores de 3 años. No obstante esta limitación, es la carrera de grado en docencia más antigua de esta universidad, y es estable en demanda y por tanto en matrícula. La carrera está creditizada, sus asignaturas son anuales y tiene práctica en instituciones educativas desde el primer año. La segunda carrera de grado con perfil docente que esta universidad ofrece es la Licenciatura en Recreación Educativa, que inició en 2014 y logró su reconocimiento oficial en el presente año. También es una carrera creditizada, con asignaturas anuales en su mayoría y otras de libre configuración; la práctica docente es a partir del segundo año. Entendemos oportuno remarcar que para el egreso de estas dos carreras, la UCU le exige al estudiante un nivel de inglés equivalente al PET de Cambridge, ofreciéndoles cursos gratuitos a aquellos que no lo poseen.

El IUACJ, por su parte, ofrece la Licenciatura en Educación Física, Recreación y Deporte, en dos sedes y con un plan de estudios de 4 años. Las asignaturas están semestralizadas y divididas en áreas: biológica, pedagógica, técnico-profesional, recreación y tiempo libre, investigación, extensión y práctica profesional.15 Por lo demás, vale decir que si bien estas dos últimas instituciones son de origen confesional, para el caso de sus carreras docentes, la formación cristiana es optativa, aunque los valores católicos forman parte de la visión de los centros.

Las expuestas son, en definitiva, las carreras docentes de grado ofrecidas actualmente por instituciones privadas en nuestro país. Exceptuando al Magisterio María Auxiliadora y la Licenciatura en Educación Inicial de la UCU, su habilitación/reconocimiento por parte del Estado uruguayo data, para todos los casos, del año 2009 en adelante.

Cerrando este apartado, entendemos oportuno mencionar que las instituciones privadas de educación superior, en lo que refiere a carreras vinculadas a la educación, incursionaron primero en las de posgrado que en las de grado, ofreciendo diplomaturas, especializaciones y

15 Desde el año 2015, la Universidad de la Empresa (UDE) ofrece la la Licenciatura en Educación Física, Deportes y Recreación. Es una carrera de cuatro años, semestralizada en su mayor parte, muy similar en su enfoque y perfil de egreso a la del IUACJ. Aún tiene pendiente su reconocimiento oficial por parte del MEC, motivo por el cual no nos detenemos en su referencia. No obstante, entendemos de orden mencionar su existencia, pues da cuenta del avance del sector privado en la formación de profesores de educación física (tres instituciones están brindando esta formación). 
maestrías desde la década de los '90. Esta oferta tuvo su curso en tanto se ofrecía una formación en educación -de posgrado- que en la época era prácticamente inexistente en la oferta estatal. Excede a nuestros cometidos actuales el análisis de estos procesos.

\subsubsection{Alteraciones al ethos de formación docente}

Si bien los programas de estudio que implementan las instituciones privadas que forman futuros docentes son los oficiales aprobados por la $\mathrm{ANEP}^{16}$ es posible identificar dos alteraciones de distinto orden vinculadas con el tránsito formativo; estas podrían agruparse en cambios estructurales y simbólicos. Los primeros refieren a la relación institución - sociedad - mercado - Estado y los segundos a las resignificaciones de sentido que los perfiles de egreso adoptan en el marco de la visión y la misión de cada una de las instituciones formadoras.

Como se indicó, las entidades educativas privadas intercambian en el mercado bienes y servicios orientados a satisfacer la obtención de certificados y títulos habilitantes para otros intercambios, también acaecidos, en el mercado. A partir de esto, la misión integracionista de las escuelas públicas, con la legión especializada de túnicas blancas, se inscribe en un área de disputa. La imagen fraguada en los institutos normales del maestro representante del Estado se pone en tensión con la de un profesional emprendedor y comprometido con cada una de las instituciones. Estos aspectos marcan una elisión central en la relación del Estado no sólo con la formación docente sino con la educación en general. En este marco, cabría interrogarse si estas instituciones privadas buscan formar un docente de élite para sus propias escuelas de enseñanza básica que endogámicamente reproduzca los capitales simbólicos preexistentes. Este aspecto, que sin duda se debe investigar particularmente, alteraría la matriz fundante de la escuela y del maestro normalista del Uruguay moderno en tanto la utopía de integración y de igualdad se tornaría evanescente.

Las diversas ofertas que se añaden al curriculum oficial (plan Plus+, plan Suma, Maestros Bilingüe, etc.) se podrían interpretar en el marco de la lógica competitiva del mercado: hacer más atractiva o exclusiva una propuesta para vender más.

Como se indicó, el segundo aspecto que interesa abordar se vincula con los procesos de resignificación de los perfiles de egreso que se producen en el marco de la misión / visión de cada una de las instituciones formadoras. En este marco, un aspecto refiere al carácter confesional que la mayoría de las instituciones formadoras tiene. "Lo trascendental", "el

\footnotetext{
${ }^{16}$ Plan Nacional Integrado de Formación Docente, aprobado por la ANEP en 2008.
} 
misterio de la vida, "la espiritualidad cristiana" y "la fe" son algunos de los rasgos diferenciales de las entidades religiosas. No obstante, el modo de significar estos aspectos es diverso en cada una de las instituciones. A modo de ejemplo, se aprecia con claridad las diferentes visiones que presentan el Instituto Magisterial María Auxiliadora y la Universidad de Montevideo. La primera de estas sostiene que “(...) se comprometen en la elaboración de una cultura que humaniza y educa a las personas para llegar a ser agentes de transformación social”"17. Por su parte la UM describe su visión indicando: “(..) que cada persona encuentre un ámbito exigente de crecimiento académico, profesional, humano y espiritual. Busca ser reconocida por la calidad de su docencia e investigación y por su internacionalidad"18. Dos aspectos se traslucen diferenciales; la primera de las instituciones ubica a la persona en clave social y con potencia transformadora. En tanto la segunda se centra en la persona individualmente, en su crecimiento y reconocimiento en función de la calidad. Indudablemente los horizontes de sentido que se delinean son antagónicos.

Por su parte el Instituto de Formación Docente Elbio Fernández también plantea que desarrolla el plan de formación 2008 aprobado por la ANEP al tiempo que ofrece tres énfasis que enriquecen su propuesta para formar maestros del siglo XXI. Marcan el profesionalismo y la calidad como rasgos vertebradores de su trabajo. Desde una misión que apunta a: “contribuir al desarrollo de personas libres, críticas, solidarias, sensibles, reflexivas y tolerantes, a través de una educación integral, laica y pluricultural"19 ${ }^{19}$ plantea que la visión:

[...] se proyecta hacia el futuro, comprometido como en su pasado, con un proyecto educativo que aspira ser paradigma en el Uruguay, en la formación de hombres y mujeres libres que, con responsabilidad, compromiso, solidaridad y excelencia académica, sean capaces de incidir eficientemente en el desarrollo de su país y la región. ${ }^{20}$

Entre otros aspectos, en el perfil se indica que se promueve una formación de excelencia, basada en el liderazgo y en el autoaprendizaje activo que se fomentará en interacción con alumnos de la Escuela Elbio Fernández.

En las articulaciones de sentido tamizadas por la misión / visión de cada una de las instituciones los aspectos vinculados a lo común que se amalgamaron, de forma particular, en el ethos del magisterio ceden lugar ante los discursos eficientistas nucleados en torno a la

${ }^{17}$ SALESIANAS LAS PIEDRAS, Identidad de las instituciones de estudios superiores. ISS-FMA. Recuperado el 30 de noviembre de 2017, de http://salesianaslaspiedras.edu.uy/identidad.html

${ }^{18}$ UNIVERSIDAD DE MONTEVIDEO, Misión, identidad y valores. Recuperado el 30 de noviembre de 2017, de http://www.um.edu.uy/universidad/mision-identidad-valores/

${ }^{19}$ ESCUELA Y LICEO ELBIO FERNÁNDEZ, Valores e identidad. Recuperado el 30 de noviembre de 2017, de http://www.elbiofernandez.edu.uy/institucion/valores-e-identidad/

${ }^{20}$ Ibídem. 
excelencia y calidad sustentados en una racionalidad de solapado corte economicista. Liderazgo y autoaprendizaje de los normalistas en interacción con los escolares de la misma institución reflejan la sospechada endogamia señalada precedentemente. Un último aspecto que interesa subrayar es la pretensión de constituirse en paradigma, así como el anhelo de incidir de manera eficaz.

\section{A modo de reflexión final}

La educación superior es un ámbito privilegiado para la generación, trasmisión y crítica del conocimiento en todas sus ramas. El actual contexto social, económico, político y cultural nos enfrenta claramente al hecho de que no es el único ámbito posible para ello. En efecto, la globalización y el impacto del neoliberalismo en la educación superior vienen determinando hace varios años ya unas nuevas dinámicas de movilidad y economía del conocimiento (Vessuri, 2008) que ponen en jaque los sentidos más clásicos de la formación terciaria (universitaria o no) y sus funciones. Estos sentidos, sedimentados en la tradición de las universidades latinoamericanas públicas, son interpelados por las nuevas lógicas economicistas que regulan el mercado y propician la emergencia de institutos de educación privados.

Claro ejemplo de lo anterior es el debate sobre la pertinencia social de la educación superior. Este debate que se da fundamentalmente entre una concepción que la restringe a la mera respuesta a demandas mercantiles y otra que la concibe como contribución a la solución de problemas sociales de carácter local y global a través de la formación de sujetos críticos, autónomos y creativos. En esta tensión, observamos como principal amenaza el enfoque neoliberal en la educación superior, como fuerza que pretende apropiarse de lo universitario considerándolo como una mercancía a la que se accede por consumo y no como una formación a la que se accede por derecho de ciudadanía (De Sousa Santos, 2009). Esta pugna de sentidos adquiere particular relevancia cuando nos referimos al sector de la educación superior encargado de formar a los docentes, dado el rol fundamental de estos en la construcción de la ciudadanía.

En este marco, la educación universitaria y terciaria privada en el Uruguay, particularmente la formación docente, ha tenido un modesto desarrollo en comparación al resto de los países del continente. No obstante, como se ha planteado, en los últimos años se observa que este desarrollo, si bien es incipiente, tiene un carácter progresivo. Instituciones confesionales y laicas sobre el plan de formación docente oficial vigente elaboran propuestas 
que buscan imprimir un plus al curriculum general para que adquiera un perfil diferencial que les permita competir en el mercado educativo.

Estas ofertas asentadas sobre las disputas por lo público y la lógica de la Nueva Gestión Pública marcan una escisión en la matriz estatista que caracterizó, inicialmente, la formación de los maestros y, posteriormente, la de profesores de educación secundaria. Los horizontes de sentido significados por un impulso integracionista de la fragmentada y diversa sociedad decimonónica necesitaron, a lo largo de todo el siglo XX, una formación de maestros que imprimiera un ethos configurado en torno a lo común y desarrollado en el marco del Estado. Como se analizó, el ejército de túnicas blancas compartía la utopía y la misión de integrar por medio de la alfabetización a todos los sujetos, urbanos y del medio rural, infantes y adultos. La figura de estos maestros se configuraba en los institutos normales públicos diseminados por todo el país con la intención de poder llegar "a todos". De esta forma el estudiante magisterial normalista guardaba una relación equivalencial con una vocación alfabetizadora e igualitarista que únicamente el Estado puede garantizar. De esta manera se procuraba integrar a la sociedad, habilitar la movilidad social de los sujetos e incentivar el desarrollo del Uruguay moderno.

Como se planteó en los apartados precedentes, la emergencia de instituciones universitarias privadas y de carreras de formación docente en el marco de estas plantea una escisión de orden estructural y simbólica. La relación sociedad - educación - Estado y el lugar de los dos últimos en la construcción de ciudadanía se alteran al ingresar la oferta privada y la lógica del mercado. Un cambio central refiere al carácter fuertemente selectivo de los estudiantes de las universidades privadas (entre ellos los de formación docente); esto implica que no todos pueden acceder sino quienes tienen un alto poder adquisitivo. Este aspecto se ha naturalizado tanto que suele omitirse en los análisis que se realizan sobre el desarrollo de la educación privada. A su vez, los cambios acaecidos en el universo simbólico refieren a la vocación integracionista e igualitarista que signó la misión de los estudiantes normalistas y los maestros. La tarea alfabetizadora, la palabra escrita, procuraba tejer una malla social común al tiempo que configuraba el ethos del docente. La lógica economicista del mercado establece otras prioridades y diseña otras sociedades que reducen los espacios y las apuestas a lo común. Asimismo, se delinean nuevos figuras docentes en las que se conjugan la misión / visión de las diversas instituciones privadas religiosas y laicas. En este escenario las relaciones equivalenciales que emergen con respecto a la formación docente se comienzan a vincular con otros significantes como eficiencia, calidad, emprendedurismo y liderazgo. El germen individualista y competitivo parecería que progresivamente ingresa en el 
proceso de resignificación del ethos de los docentes y de esta manera los tradicionales procesos de producción y reproducción educativa se hallan amenazados.

\section{REFERENCIAS}

ALLIAUD, Andrea. Los maestros y su historia: los orígenes del magisterio argentino/1. Buenos Aires: Centro Editor de América Latina S.A. 1993.

BANCO MUNDIAL. La enseñanza superior: las lecciones derivadas de la experiencia. Washington: Banco Internacional de Reconstrucción y Formento /BM. 1995.

BARRÁN, José Pedro. Historia de la sensibilidad en el Uruguay. Tomo 2: El disciplinamiento (1860-1920). Montevideo: Banda Oriental-FHCE. 1990.

BENTANCUR, Nicolás. Las reformas educativas de los años noventa en Argentina, Chile y Uruguay. Racionalidad política, impactos y legados para la agenda actual. Montevideo: Banda Oriental. 2008.

BORDOLI, Eloísa. La construcción de la relación pedagógica. Sujetos, saber y gobierno de los niños. Montevideo: FHCE, UdelaR. 2015.

BOURDIEU, Pierre. Poder, Derecho y clases sociales. Bilbao: Desclée de Brouwer. 2000.

BROVETTO, Jorge. Formar para lo desconocido: apuntes para una teoría y práctica de un modelo universitario en construcción. Montevideo: UdelaR. 1994.

BURGUES, Christian. Con las alas ancladas. Ensayo sobre los deberes y restricciones que impone una universidad (re-) pública. En: VISCARDI, Ricardo \& DÍAZ GENIS, Andrea.

Filosofías de la universidad y conflicto de racionalidades III Teoría de la universidad II Presente universitario y conflicto de racionalidades. Montevideo: Universidad de la República,2010. ISBN 978-9974-0-0729-1. CD ROM.

DELIO, Luis. Historia de la formación docente: la enseñanza normal nacional. Tomo I. 1.ed. Montevideo: Cruz del Sur. 2009.

DEMARCHI, Marta. Formación docente: surgimiento y perspectivas. Montevideo: Revista de la Educación del Pueblo. 1996.

DIKER, Gabriela; TERIGI, Flavia. La formación de maestros y profesores: hoja de ruta. Buenos Aires: Paidós. 2008.

DIRECCIÓN GENERAL DE INSTRUCCIÓN PRIMARIA. Anales de Instrucción

Primaria, $\mathrm{n}^{\circ}$ 1-2, tomo I. Montevideo: Barreiro y Ramos. 1903.

DIRECCIÓN GENERAL DE INSTRUCCIÓN PRIMARIA. Anales de Instrucción

Primaria, n $^{\circ}$ 3-4, tomo II. Montevideo: Barreiro y Ramos. 1904.

GAJARDO, Tatiana. Educación privada vs. Educación pública en Santiago de Chile: una reflexión necesaria. En: GENTILI, Pablo \& LEVY, Bettina. (Comps.). Espacio público y 
privatización del conocimiento: estudio sobre políticas universitarias en América Latina. Buenos Aires: CLACSO.2005. p. 163-203.

GENTILI, Pablo y LEVY, Bettina. (Comps.). Espacio público y privatización del conocimiento: estudio sobre políticas universitarias en América Latina. Buenos Aires: CLACSO. 2005.

GENTILI, Pablo. América Latina, entre la desigualdad y la esperanza: crónicas sobre educación, infancia y discriminación. Buenos Aires: Siglo XXI. 2015.

GENTILI, Pablo. Desencanto y utopía: la educación en el laberinto de los nuevos tiempos. Caracas: Fondo Nacional de Ciencias, Tecnología e Innovación- Centro Internacional Miranda. 2007.

GENTILI, Pablo. Pedagogía de la igualdad: ensayos contra la educación excluyente. Buenos Aires: Siglo XXI. 2011.

LACLAU, Ernesto. Emancipación y diferencia. Buenos Aires: Ariel. 1996.

LACLAU, Ernesto. \& MOUFFE Chantal. Hegemonía y estrategia socialista. Hacia una radicalización de la democracia. Buenos Aires: FCE. 1987.

LANZARO, Jorge. La segunda transición en el Uruguay en CAETANO, Gerardo. (comp.) (2005). 20 años de democracia Uruguay 1985-2005: miradas múltiples (pp. 341-345). Montevideo: Taurus. 2005.

MENA SEGARRA, Enrique, PALOMEQUE, Ágapo \& DELIO, Luis. Historia de la educación uruguaya. Tomo 2 . La educación uruguaya 1830 - 1886. Montevideo: de la Plaza. 2011.

MOREIRA, Constanza. La reforma de Estado en Uruguay: cuestionando el gradualismo y la heterodoxia. En: CALAMÉ, P. \& TALMANT, A. (comps.). Con el Estado en el corazón. El andamiaje de la gobernancia (pp. xx-xy). Montevideo: Trilce. 2001.

MUÑOZ, Manuel. Pertinencia y nuevos roles de la Educación Superior en la región. En: UNESCO. La educación superior en América Latina y el Caribe: diez años después de la Conferencia Mundial de 1998. Cali: UNESCO IESALC, 2008. p. 223-266.

NAIDORF, Judith. La privatización del conocimiento público en universidades públicas. En: GENTILI, Pablo. \& LEVY, Bettina. (Comps.). Espacio público y privatización del conocimiento: estudio sobre políticas universitarias en América Latina. Buenos Aires: CLACSO.2005. p. 101-161.

PUIGGRÓS, Adriana. Sujetos, disciplina y currículum en los orígenes del sistemameducativo argentino (1885-1916). Buenos Aires: Galerna. 1990.

SOUSA SANTOS, Boaventura. El rol de la universidad en la construcción de una globalización alternativa. En: GUNI. La educación superior en tiempos de cambio: nuevas dinámicas para la responsabilidad social. Madrid: Mundi-Prensa, 2009. p. 44-45. 
TÜNNERMANN, Carlos; DE SOUZA CHAUI, Marilena. Desafíos de la Universidad en la Sociedad del Conocimiento, Cinco Años después de la Conferencia Mundial sobre Educación Superior. En: Foro de la UNESCO. París: Comité Científico Regional para América Latina y el Caribe, 2003. Disponible en: http://www.unachi.ac.pa/assets/descargas/planificacion/doc-8desafios_la_universidad.pdf. Acceso en: 8 jul. 2017.

UNESCO. Conferencia Mundial sobre la Educación Superior. La educación superior en el siglo XXI: Visión y acción. París: UNESCO. 1998.

URUGUAY. Ley No 18.437, Ley General de Educación, del 12 de diciembre de 2008. Poder Legislativo, 2008. Disponible en:

https://legislativo.parlamento.gub.uy/temporales/leytemp6053071.htm. Acceso en: 30 nov. 2017.

URUGUAY. Ordenanza N $\mathrm{N}^{\circ} 14$ Normas de habilitación de establecimientos privados de educación y Protocolo de habilitación de centros privados, del 19 de diciembre de 1994. ANEP, 1994. Disponible en:

http://www.anep.edu.uy/anep/phocadownload/normativa/Ordenanza\%2014.pdf. Acceso en: 2 dic. 2017.

VARELA, José Pedro. La legislación escolar. Montevideo: El Siglo Ilustrado. 1990 a.

VARELA, José Pedro. La educación del pueblo. Montevideo: El Siglo Ilustrado. 1990 b.

VESSURI, Hebe. De la pertinencia social a la sociedad del conocimiento. En: UNESCO. La educación superior en América Latina y el Caribe: diez años después de la Conferencia Mundial de 1998. Cali: UNESCO IESALC, 2008. p. 459-478.

\section{SOBRE OS AUTORES:}

\section{Eloísa Bordoli}

Doutora en Ciencias Sociales, Universidad de la República - Uruguay. Facultad de Humanidades y Ciencias de la Educación. Grupo Investigación: "Políticas Educativas, Curriculum y Enseñanza”. E-mail: eloisabordoli@gmail.com

\section{Luis Domínguez}

Universidad de la República - Uruguay. Facultad de Humanidades y Ciencias de la Educación. Lic. en Ciencias de la Educación. E-mail: luis.dom2010@ gmail.com 